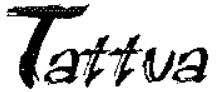

JOURNAL OF PHILOSOPHY

\title{
WHITEHEAD AND HIGHER EDUCATION: TRANSFORMATION THROUGH PROCESS
}

\section{Thomas Chathamparampil}

\section{Introduction}

Alfred North Whitehead, one of the twentieth century's most original metaphysicians and a major figure in mathematical logic, proposed a general philosophical position, which he called "the Philosophy of Organism." It insists upon the ultimate reality of things in relation, changing in fime, and arranged in terms of systems of varying complexity, especially living things, including living minds. 'Whitehead's philosophy, popularly known as 'process thought', has influenced many fields of study, especially philosophy and theology. ${ }^{2}$ Attempts are being seriously pursued to establish process thought as a meaningful foothold in basic and applied fields of study. Education is one field wherein process thought finds large possibilities of application.

The purpose of higher education is largely based on the accumulated knowledge of the past, which builds on current realities and creatively processes them to project future goals. Higher education generally is now being influenced by globalization characterized by advancements in information and communication technologies, scientific developments leading to knowledge explosion, global networking, culfural diversity, and international commerce and business. 
These global changes challenge educational system to integrate the realities of the transforming world, and to articulate and re-articulate the goals and objectives of higher education. The 7th International Whitehead Conference 2009 is timely in calling for the analysis of the fundamentals of 'process-education', as there is no escape path for higher education in lieu of competition, efficiency and output.

\section{Whitehead's View on Education}

Education, in general, aims at producing men and women, who possess both culture and expert knowledge in some special direction. Culture, for Whitehead, is "activity of thought, and receptiveness to beauty and humane feeling." 3 Concerning activity of thought, the teachers should be cautious of what Whitehead calls "inert ideas, that is to say, ideas that are merely received into mind without being utilized, or tested, or thrown into fresh combinations." Education, which is radically engaged with 'inert ideas', is not only useless, but also harmful. Keeping knowledge alive and preventing it from being 'inert' would, therefore, become the central task of education that is process-oriented.

Hence, first of all, the students are to be introduced into the main ideas, which are important in life, so that they could make them their own, and apply them 'here and now' in the actual situations of life. In other words, the students should experience from the beginning the 'joy of discovery' in their lives, for education is the acquisition of the art of the utilization of knowledge. By 'utilization of knowledge' means 'relating it to the main stream of life, with all its perceptions, feelings, hopes, desires and thoughts'. The utilizalion of knowledge, however, depends on various factors, such as the genius of the teacher, the intellectual capacity of the students, their prospects in life, the opportunities offered by the society, etc. All the same, the success of the process of knowledge application essentially depends on the character of the students and the genius of the teacher'.

Secondly, education should insist on the significance of the 'present': "The present confains all that there is. It is the holy ground; for it is the past, and it is the future." 4 For, we are not dealing with dead matter, but human mind, which is "a perpefual activity, delicate, receptive and responsive to stimulus." Hence the golden rule of education is: "Whatever interest attaches to your subject matter must be evoked here and now; whatever powers you are strengthening in the pupil, must be exercised here and now; whatever possibilities of mental life your teaching should impart, must be exhibited here and now."

Thirdly, education should help cultivate the most austere of all metal qualities, namely "the sense of style." Style, in the words of Whitehead, "is an caesthetic 
sense, based on admiration for the direct attainment of a foreseen end, simply and without waste." Style, which involves both the qualities of 'attainment and restraint', is the last acquirement of the educated mind; it is also the most useful. Style would help one to attain end without raising undesirable effects and consequences. With style one's power is increased, and one is likely to attain one's object without being distracted with irrelevancies. However, style, for Whitehead, is the exclusive privilege of the expert; the peculiar contribution of specialism to culfure. Hence style is something to be nurtured, as it acknowledges the true character of oneself, and what one is capable of contributing in a unique way.

Finally, the essence of education is that it be "religious." In order to avoid all sorts of confusion associated with the term "religious," Whifehead himself explains what religious education is about: "A religious education is an education which includes duty and reverence." Duty arises from our potential control over the course of events. [...] And the foundation of reverence is the perception that the 'present' holds within itself the complete sum of existence, backwards and forwards that whole amplitude of time, which is eternity." 7

\section{Dimensions of University Education}

University education has become a powerful 'movement of honour' in all the countries of the world. In fact universities have now become the cradles to nurture and strengthen the new generation to survive the crude realities of existence. Accordingly higher education is challenged to move from having mere academic and administrative autonomy towards a more innovative enterprise in university services. The projections are indicative of a large mobility of scholars, academicians and students across the globe, leading to more commonality and equivalence of educational delivery and output in terms of competencies. The above global scenario thus calls for changes from the traditional mode of university education to a more dynamic, result-oriented system, which would ensure the ability to sustain the issues of leadership, governance and the academic strategy of modern universities. ${ }^{8}$

\section{a) Focus on Leadership}

The mainstay of leadership-focus of universities has been predominantly centered on teaching, research and training. This, however, will be subjected to a transformation, or a process of creating not only a human potential that is workable, but also a human power that is marketable in emerging global skill needs. This shift of emphasis will subsequently look at creating human potential that will ensue in enhanced skills and professionalism. 
Firstly, transformation, as far as the approaches to education are concerned, will largely depend on transforming the knowledge orientation of higher education, by moving from 'humanistic' to more technological and professional dynamics. Traditional courses and progarmmes will now be challenged by more competing influences of education that are not mere waterlight compartments, but more interdisciplinary or multi-disciplinary in approach and application. The leadership of universities will, therefore, have to re-arliculate their mission, which would facilitate a 'process' of growth and progress.

Secondly, attention on 'education for sustainability' as an emerging field of understanding is necessary for leaders to engage in and to navigate towards a bright future. As a manifestation of process thought, education for sustainability aims to be transformative, to engage both educators and learners in the process of becoming active participants and decision makers in their journey, along the susfainability poth. Leadership in the universities should strive to facilitate this process, encourage educators to learn new skills, including ways of collaboraling, negotiating and building partnerships with those they engage with. In line with this thought, Sterling strongly advocates educational transformation towards sustainable education and argues for the re-orientation of educational policies, programmes and practices using the synergy between ecological and systemic thought. ${ }^{9}$ Sterling suggests that we need to undertake an educational joumey from the present to the future, teaching pedagogies that practice sustainable education.

The concerns of sustainability should be reflected in the maintenance of a dominant paradigm, its values and modus operandi. In formal education, there is rather a minimal effect of sustainability concepts and values on the institution and on the behaviour of teachers and students. Sustainability concepts, such as 'biodiversity', may be added as parts of the curricula, which, in other respects, carry (consciously or unconsciously) messages supporting or reflecting un-sustainability. ${ }^{10}$

The response to the challenge of sustainability is 'learning as maintenance' resulting in an accommodative 'education about sustainability' in policy and practice, which is widely believed to be sufficient. Critical reflection on the assumptions and values of the 'theory in action', resulting in an attempted 'building-in' of sustainability ideas to, and re-orientation of the existing system, will have to be looked into as a reformation process.

A change of social paradigm amongst educational actors towards the ecological worldview, including a strong, but critically open interpretation of sustainability, will be crucial. Education should be re-conceived and re-designed - through a continuous learning process - to embody and reflect a whole systems approach, 
and what is generally understood as sustainability. This response emphasizes process and the quality of learning, which is seen as essentially creative, reflexive and participative. The shift in focus towards 'learning as change' will engage the whole person and the whole community, whereby the meaning of sustainable living is continually explored and negotiated through, as far as possible, living it.

\section{b) University Governance}

As changes impact education and leadership of universities, new layers and platforms for structural changes in organization of higher education will emerge. Governance initially will have to re-structure its thrust on research and knowledge creation. To solve complex problems of life in all its manifestations, we will have to break the traditional structures of compartmentalism, creating sufficient scope for interdisciplinary and multidisciplinary educational programmes. The new domains that emerge will be process-oriented and will eventually shape the evolving siructures, dominated by sciences and disciplines with their capacity to integrate and transform. Possibilities will be wide open for the specialists and generalists to determine their own levels of knowledge thresholds.

Understanding of re-organizing universities in terms of emerging trends is tikely to lead us to new insights into the nature of their complexity. The present scenario will be characterised by a process of ever-evolving changes that determine the style of education by global reforms and recommendations. The effectiveness of a university will depend on its ability to cope with those factors which make educotion renewed with vigour and vitality. Humankind sees in proper education an indispensable asset in its attempt to attain the ideals of peace, freedom and social justice, as education for life is based on four pillars: (i) learning to know, (ii) learning to do, (iii) learning to live together, and (iv) learning to be. 'Learning to know' challenges education to respond to rapid changes in all walks of human progress and development, and to integrate broad general education with specific disciplines for an ongoing/life-long education. The restructuring process will need to focus on acquisition of competencies that enable individuals to deal with a variety of complex situations, as 'learning to do'. 'Learning to live together' emphasizes the possibilities to prevent violence and conflict, although education has not so far done enough to mitigate this situation. Besides the need for greater self-knowledge through education, it should also contribute to an individual's complete development as 'learning to be'."

Governance of universities will also face problems of attracting world-class research, integrating the faculty, the researchers and the students. ${ }^{12}$ Technology investments and infrastructure defermine new dimensions of change, but the key to successful 
governance will depend on the capability to adapt quickly to changes that arise out of global competitions. Such systemic changes will thrive on the processing of information and the rapid creation of knowledge, which will scale the level of productivity and efficiency.

\section{c) Academic Strategy}

The ability of universities will change with new requirements of quality in education than a quantitative expansion of service providers. Quality of education, which does not any longer dwells on 'being progressive', will have to confront the challenges of 'liberating education'. Liberating education can affirm freedom and the capacily of people to decide their own desfinies. It is a critical but creative process through which the culture of silence is overcome and shattered. Paulo Freire saw the moral potential in a transformative education, the potential to liberate. According to him, knowledge emerges only through invention and re-invention, and through the restless, impatient, continuing, hopeful inquiry men and women pursue in the world, with the world, and with each other. ${ }^{13}$

Freire's ideas of education, founded on conscientization and dialogue, assume a strong belief and faith in the struggle for equalily and social justice. ${ }^{14}$ Advocating conscientization and dialogue would indicate a shiff from the educator as the subject of process to the learner. The raison d'etre of liberating education lies in its drive fowards reconciliation. Education must begin with the solution of the feacherstudent polarity, by reconciling the poles of the opposition, so that both could be simultaneously teachers and students. In this process of learning, that is complex and adaptive, personal change in epistemic assumptions is absolutely essential to any major breakthroughs in decision making. Epistemic learning involves deliberate breaking down and restructuring of mental models that support worldviews. ${ }^{16}$ The dynamics of epistemic learning involves each learner to go through a period of chaos, confusion and being ovenwhelmed by complexity before new conceptual information brings about a spontaneous process resulting in restructuring of mental models at a higher level of complexity, thereby allowing a learner to understand concepts that were formally opaque. ${ }^{15}$

\section{Rationality of University Education}

Jusf like any other educationists, Whitehead would agree that universities are schools of education and research. But, unlike others, he believes that the primary task of a university is neither to convey knowledge to the students nor to offer opportunities of research to the faculty. "The justification for a university," Whitehead writes, "is 
that if preserves the connection befween knowledge and the zest of life, by uniling the young and the old in the imaginative consideration of learning. ${ }^{16}$

Indeed the university should impart information, but it should impart it imaginatively. The university should convey knowledge, but it should convey imaginatively. For, imaginative consideration would generate an atmosphere of excitement and would fransform information and knowledge. Subsequently a fact is no more a bare fact, but is invested with all possibilities. Imagination is a way of illumining the facts, by eliciting the general principles which apply to the facts, and by surveying alternative possibilities which are consistent with those principles. This imaginative process enables men and women "fo construct an intellectual vision of a new world, and to preserve the zest of life by the suggestion of satistying purposes. ${ }^{17}$

Imagination, in Whiteheadian terms, "is a contagious disease," which cannot be delivered to the students by the faculty, but it can only be communicated by the members of the faculty, who acquire knowledge with imagination, like a lighted torch which passes from hand to hand down the generations. However, imagination cannot be acquired once and for all, for imaginative life is "a way of living." Hence a university, as a centre of education and research, should nurture the habit of learning with imaginotion. If the teachers want to be imaginative, they should engage in research; and if the researchers want to be imaginative, they should be brought into intellectual sympathy with the young, who are in the most imaginative period of life.

Indeed youth is the most imaginative; but they lack the discipline of imagination. On the contrary, if the imagination of the youth can be strengthened by disciplined training, the power of imagination can be preserved throughout life. But the tragedy of the world is that those who have imagination lack experience and those who have experience have feeble imaginations. The task of the university, therefore, is to "weld together imagination and experience,"18 education, which is discipline for the adventure of life, and research, which is intellectual adventure. In fact the university should be a home of adventure shared in common by young and old.

The welding/combination of imagination and experience requires some sort of leisure, freedom from resiraints and harassing worries, the excitement of curiosity and the sense of self-confidence deriving from a sense of pride in the achievements of the humanity due to the advance of knowledge. In Whitehead's wild imagination, "the faculty should be a band of scholars, stimulating each other, and freely determining their various activities. ${ }^{19}$ That is why, perhaps, Whitehead branded imagination as "a dangerous gift, which has started many a conflagration." However, he rightly thinks that it is a gift which all must pray for their country; it is a gift 
universities have to offer to the learned; the gift of imagination - the lighted torch which passes from hand to hand.

\section{Conclusion}

Process thought, no doubt, provides us with an alternative paradigm to deal with the consequences of changes, impacting higher education and its ability to respond to the various aspects that relate to leadership, governance and the academic strategy of universities. The interconnectedness among these entifies of universities is very crucial, as process applications are bound to stimulate learning systems and approaches for quality/efficiency of education in universities to transform and sustain themselves. For higher education to rise to the challenges of the times, the onus will rest on university leaders to use process with a great deal of dynamism to stimulate and transform students, and to set up structural adjustment in governance to make process relevant today.

\section{Notes:}

1. A.N. Whitehead, The Nalure of Educalion, Educational Development and the Rhythm of Growh, Universities and Professional Training. <hitp://education.stateuniversity.com/pages/ 2548/Whitehead-Alfred-Norh-1861-1974.hIml>

2. "What is process thought?" Process Studies 31/1 (2007), 34.

3. A.N. Whitehead, The Aims of Educalion and Other Essays (New York: The Free Press, 1929), 1.

4. A.N. Whitehead, The Aims of Education, 3.

5. A.N. Whitehead, the Aims of Education, 6.

6. A.N. Whitehead, The Aims of Education, 12.

7. A.N. Whitehead, The Aims of Educotion, 14.

8. Globalizalion and Calholic Higher Education, Congregation de Insfilutione Catholica Federatio Internotionolis Universitatum Catholiconum, CIC-FIUC, Working Document 2004.

9. Centre for Research in Educotion and the Environment [CREE] 2005 Re-lhinking education and learning to address the challenge of sustainability, University of Bath Press Release <htlp://vww.bath.ac.uk/cree/ sterling/Sterling/Universily of Bath Press Release.doc>

10. Whole Systems Thinking as a Basis for Paradigm Change in Educalion: Explorations in the Context of Sustoinabilily. Doctoral thesis: <hltp://www.bath.ac.uk/cree/sterling.htm>

11. Jean Jacques Delors, Education: The Necessary Utopia, Learning: The Treasure Within: Report to UNESCO of the Internalional Commission on Education for the Twenly-first Century, 1996.

12. A Preliminary Report of Findings and Recommendalions, New York Stole Commission on Higher Educalion, 2007. 
13. Paulo Freire, Pedagogy of the Oppressed (Hormonsdworth, Penguin, 1972), pp. 45-46, 52-53, 56-57.

14. Juma E. Nyirenda, The Relevance of Paulo Freier's Contributions to Educolion and Development in Present Day Africa, Dept of Adull Educalion, University of Bolswona, Gaborone, Botswana, <htip:// archive.lib.msu.edu/ DMC/Alrican Journals/vollonol>

15. M. Salner, Adult Cognitive and Epistemological Development in Syslems Educotion. Syslems Research 3, (1986), 225-32.

16. A.N. Whitehead, the Aims of Education, 93.

17. A.N. Whitehead, The Aims of Education, 93.

18. A.N. Whitehead, The Aims of Education, 93.

19. A.N. Whitehead, The Aims of Education, 99. 